\title{
MR Fingerprinting
}

National Cancer Institute

\section{Source}

National Cancer Institute. MR Fingerprinting. NCI Thesaurus. Code C162644.

A novel application of magnetic resonance imaging. Instead of using a repeated, serial acquisition of data for the characterization of individual parameters of interest, MRF uses a pseudorandomized acquisition that causes the signals from different materials or tissues to have a unique signal evolution or "fingerprint" that is simultaneously a function of the multiple material properties under investigation. The processing after acquisition involves a pattern recog nition algorithm to match the fingerprints to a predefined dictionary of predicted signal evolutions. These can then be translated into quantitative maps of the MR parameters of interest. 